\title{
Influence of micro-crack on the propagation of a semi-infinite crack
}

\author{
Hamid Hamli Benzahar ${ }^{1}$, Abderrazak SAID ${ }^{2}$, and Mohamed CHABAAT ${ }^{3}$ \\ ${ }^{1}$ University of Djillali Bounaama \\ ${ }^{2}$ Affiliation not available \\ ${ }^{3} \mathrm{USTHB}$
}

August 4, 2020

\begin{abstract}
The main objective of this research is to determine the influence of micro-crack on the propagation of a semi-infinite crack. This study is mainly based on the determination of the strain energy during the interaction between the semi-infinite crack and the neighboring microcrack. The problem is formulated by a plane element, having a micro-crack varies around itself and around a semi-infinite crack. The cracked element is subjected to a uniform load according to mode I. The theoretical analysis of the strain energy is based on the stress found during the propagation of the semi-infinite crack. During the positioning of the micro-crack with respect to the semi-infinite crack, according to the strain energy results, the presence of the micro-crack can amplify, reduce and sometimes arrest the propagation of the semi-infinite crack.
\end{abstract}

\section{Introduction}

The interaction between the semi-infinite crack and a neighboring micro-crack has been studied by several researchers [1-3]. In this paper, based on the strain energy, this study is devoted to determining the influence of microcrack on the semi-infinite crack. During the propagation of semi-infinite crack, the strain energy is mainly based on the stress field found by H. Hamli benzahar [4]. The problem is formulated by a brittle material of a thin thickness, cracked at the end, having a microcrack varies around itself by an angle $\alpha$ and around d the semi-infinite crack by an angle (see Figure 1). The cracked model is subjected to a uniform load making opening of semi-infinite crack according to the first mode of rupture (Mode I). Using the mathematical approaches, the constraints and strains fields of a micro-crack and semi-infinite crack are formulated by using of the complex potentials theory [5]. The strain energy rate is defined as the energy released during the cracking of a brittle or ductile material [6]. To determine the evolution of the semi-infinite crack, several researchers used the principle of J-integral [7-8]. Experimental and numerical results show that macroscopic specimens which contain microscopic defects producing local stress concentrations [9-10]. In brittle materials, the failure is considered to be an energy-consuming phenomenon, taking into account the energy state of the atoms before and after cracking. [11]. This study is divided to two parts;

- The first part is devoted to the study of the orientation of the microcrack around the semi-infinite crack according to the angle, whose strain energy is determined for each position of the microcrack.

- On the other hand, the orientation of the microcrack around itself (according to the angle $\alpha$ ) is studied in the second part.

According strain energy results, the positioning of the microcrack can amplify, reduce and sometimes stop the propagation of the semi-infinite crack. 


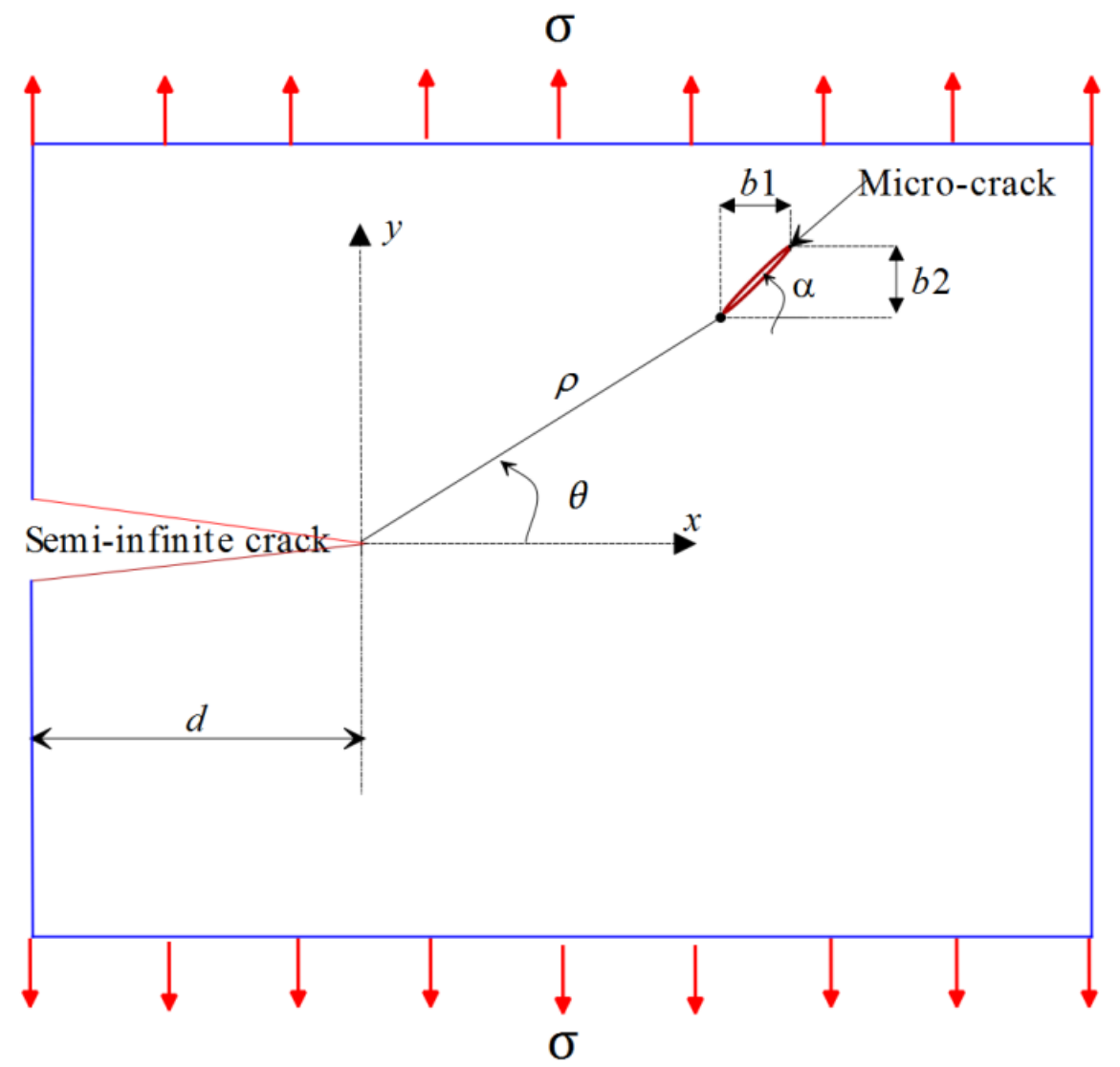

Fig. 1 Presence of semi-infinite crack and microcrack in the plane element

where $\rho$ : distance between the semi-infinite crack and micro-rack. $d ;$; semi-infinite crack length. $b_{1}$ and $b_{2}$; dimensions of the micro-crack along the $x$ and y axis successively.

\section{Brittle failure}

The brittle failure occurs suddenly by cleavage generated during separation of the atoms forming the material [12]. In brittle metals, it is experimentally observed that failure only occurs if the material plasticizes, which shows that microcracks or defects are created during the plasticization of the material [13]. The sudden failure strength of a brittle material is determined by the critical value of the stress intensity factor in mode I $\left(\mathrm{K}_{\mathrm{I}}\right)$. It varies according to the chemical composition and the property of the cracked material [14]. The stress intensity factor in mode I, can be linearly calculated by the stresses which tend towards infinity at the end of semi-infinite crack [15]. It makes to determine the size of microcrack and effective in stopping of the cracking and consequently controlling the necessary and sufficient qualities [16]. The $\mathrm{K}_{\mathrm{I}}$ represents a physical characteristic of the material determined experimentally under conditions [17]. In linear elasticity, the distribution of the plane stresses in the vicinity of the semi-infinite crack is expressed in polar coordinates [18] :

$\sigma_{\mathrm{ij}(r, \theta)}=\frac{K_{\mathrm{ij}(r)}}{\sqrt{2 \pi r}} f_{\mathrm{ij}(\theta)}(1)$

\section{1 Brittle failure theory}

For a element of elastic material having a semi-infinite crack, the propagation of this one modifies the surface of their lips. Griffith [11] approached the energy problem and thus proposed a theory of failure based on 
energy consumption during the crack propagation process. The total energy conservation of the cracked system is given as follows [19]:

$d W_{t}=d W_{e}+d W_{\mathrm{ex}}+d W_{s}+d W_{k}=0(2)$

where, $d W_{e}$; elastic energy, $d W_{\text {ex }}$; potential energy due to external forces, $d W_{s}$; separation energy, $d W_{k}$; kinetic energy.

In case of kinetic energy greater than zero $\left(d W_{k}>0\right)$, the semi-infinite crack will unstably propagates. The energy rate is defined as being the energy released during the propagation of the semi-infinite crack [20]. By definition, it is given as follows:

$G=-\frac{\partial}{\partial S}\left(W_{e}+W_{\text {ex }}\right)(3)$

According to Griffith [11], the propagation of the semi-infinite crack is ensured when the energy rate is greater than twice the characteristic surface energy of the material $(G>2)$. Irwin [21] used the term surface energy or energy absorbed in the fracture process to apply it to plastic materials. It also showed that at the crack tip, there is a relation between the strain energy rate and the stress intensity factor.

\section{2 Different modes of fracture}

The semi-infinite crack can propagates according to three modes of displacement of the lips of the opening [22]. It can also be propagated according to the mixed mode representing the superposition of two or three modes [23]. Figure 2 illustrates the three modes of displacement of the crack lips. In the first mode of fracture (Mode I), the surfaces of the semi-infinite crack tends to step aside perpendicularly with respect to the plane of crack [24]. Mode II is considered, if the surfaces of the semi-infinite crack slide between it parallel to the plane of crack [25]. On the other hand, mode III occurs when the surfaces of semi-infinite crack slide between it perpendicular to those of mode II [26].

Fig. 2 three modes of fracture

For each mode of fracture, the stress intensity factor is determined as a function of the component of constraints. When the point of application of constraints tends towards zero $(r-0)$, the stress intensity factor is found as follows:

\{

$$
\begin{gathered}
K_{I}=\sqrt{2 \pi r} \sigma_{22} \\
K_{\mathrm{II}}=\sqrt{2 \pi r} \sigma_{21} \\
K_{\mathrm{III}}=\sqrt{2 \pi r} \sigma_{23}
\end{gathered}
$$

\section{3 Elastic deformation of material}

The deformation of a material is generated during that is subjected to mechanical stresses. it characterizes the behavior of the material [27]. The deformation capacity of an element depends on the nature of the material and shape of the piece while respecting the manufacturing processes [28]. The Figure 3 shows a volume element subjected to triaxial traction along the $\mathrm{x}, \mathrm{y}$ and $\mathrm{y}$ axes. 


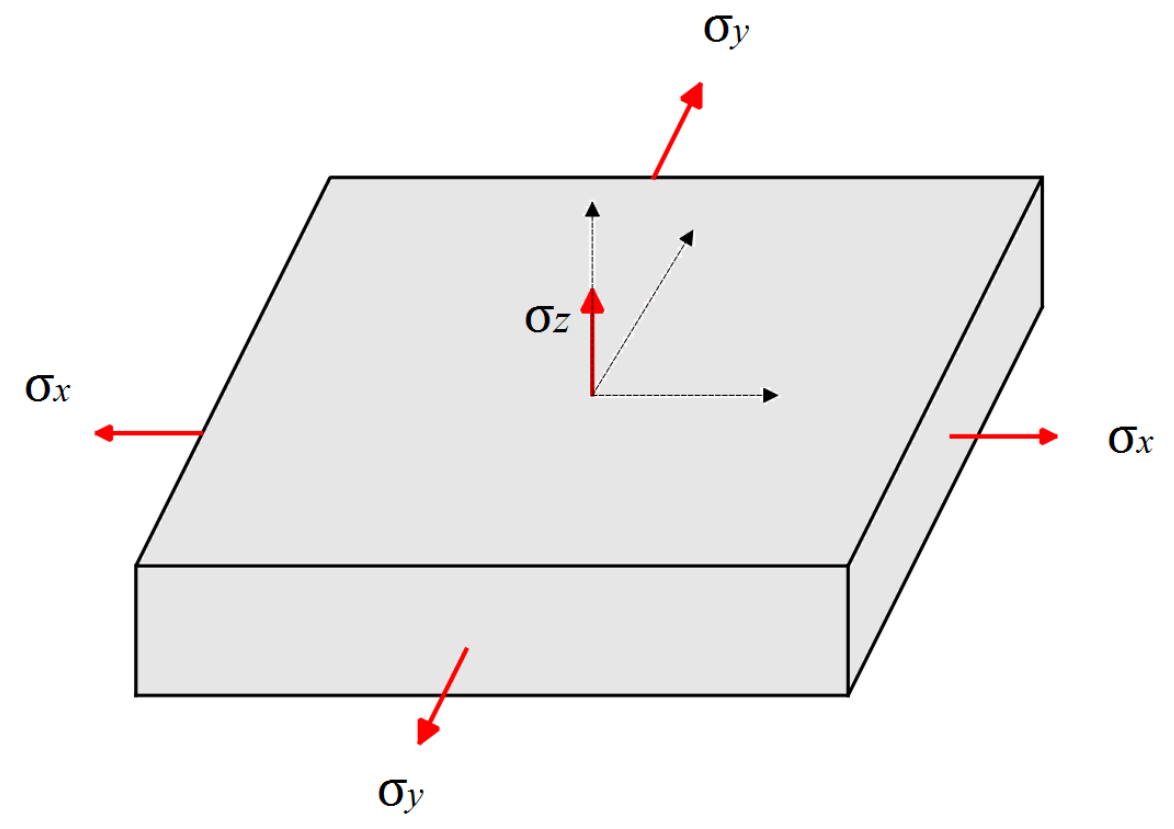

Fig. 3 Traction of an volume element

To determine the deformations corresponding to the stresses applied to this volume element, we use the principle of superposition [29]. The elastic deformation of a material is only given with constraints, the relationship between stress and strain can be written in the following matrix form:

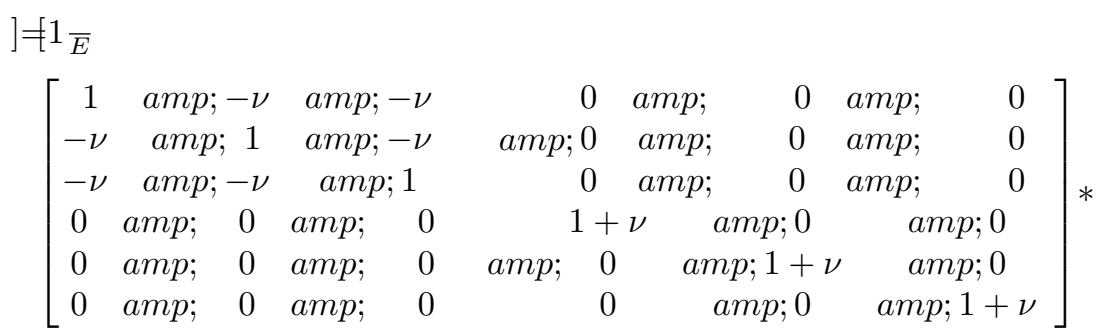

] (5)

where $\varepsilon_{\mathrm{ij}}$; axial strain, $\nu$; poisson ratio, E ; elasticity modulus of material.

\section{Interaction between microcrack and a semi-infinite crack}

The interaction between microcrack and a semi-infinite crack, generates a high concentration of stress, straints and displacements at the crack tip [30]. The semi-infinite crack is determined by their length $(l)$. On the other hand, the microcrack is defined by Burger's vector $\left(b=b_{x}+i b_{y}\right)$. During the propagation of a semi-infinite crack towards the neighboring microcrack, a damage zone surrounding the initial crack occurs with a high concentration of stresses. It is considered to be a highly disturbed area and also called the fracture process zone [31]. The extension of semi-infinite crack is envisaged in a small zone near to the initial crack in which, a strain energy is released [32]. The elastic behavior of cracking during the presence or absence of micro-crack has been studied by several researchers from various disciplines such as metallurgy, mechanics, physics [33-35]. In our case, the interaction is ensured by a semi-infinite craeck with a neighboring microcrack varies around the crack tip with angle and around itself with angle $\alpha$ (see Figure 1 ). The loading is applied according to the first mode of fracture which opens the crack perpendicular to their lips (Mode I). 
The mathematical problem of the interaction (crack-dislocation) is formulated in terms of complex potentials of plane stress [36]. The total plane constraints generated by this interaction, are given as a function of global complex potentials;

$\sigma_{11}+\sigma_{22}=2\left[\phi_{O}^{\prime}(z)+\phi_{O}^{\prime}(z)\right](6)$

$\sigma_{22}-\sigma_{11}+2 i \sigma_{12}=2\left[z \phi^{\prime \prime}{ }_{O}(z)+\psi_{O}^{\prime}(z)\right](7)$

with

$\phi_{O}(z)=\phi_{\mathrm{SIC}}(z)+\phi_{d}(z)(8)$

$\psi_{O}(z)=\psi_{\mathrm{SIC}}(z)+\psi_{d}(z)(9)$

where $\phi_{\mathrm{SIC}}(z), \psi_{\mathrm{SIC}}(z)$; complex potential functions of semi-infinite crack. $\phi_{d}(z), \psi_{d}(z)$;

complex potential functions of microcrack, $\phi_{\text {Int }}(z), \psi_{\text {Int }}(z)$; presentents the complex

potential functions of the interaction between semi-infinite crack and microcrack.

\section{III.1 Constraints field}

The constraints field generated during the interaction between the semi-infinite crack and neiboring microcrack, represents the superposition of two constraints fields produced by the semi-infinite crack and the microcrack [37]. The constraints found at semi-infinite crack tip, are characterized by a factor called stress intensity factor (SIF). The orientation of microcrack around semi-infinite crack, can generate the stress and consequently release the energies in each zone of the material [38]. Using Equations (6) to (9), H. Hamli Benzahar [4] determined the constraints field of interaction between microcrack and a semi-infinite crack in the following form:

$\sigma_{11}=\frac{2 \mu b}{\pi(1+k) \rho}[4 \sin (\alpha-\theta)-\sin (\alpha+\theta)-\sin (\theta) \cos (\alpha-2 \theta)](10)$

$\sigma_{22}=\frac{2 \mu b}{\pi(1+k) \rho}[\sin (\alpha+\theta)+\sin (\theta) \cos (\alpha-2 \theta)](11)$

$\sigma_{12}=\frac{2 \mu b}{\pi(1+k) \rho}[\cos (\alpha+\theta)-2 \sin (\alpha-\theta)+\sin (\theta) \sin (\alpha-2 \theta)](12)$

\section{2 Strain energy release}

The semi-infinite crack propagates during the rate of release of the stored elastic strain energy is equal to the rate of creation of strain energy of the crack area [39]. The released strain energy is defined as being the released energy during the propagation of the semi-infinite crack at presence of a neighboring dislocation [40]. Based on the energy state of atoms before and after cracking, Griffith has shown that failure is an consuming phenomenon of energy [11]. Using mathematical approaches, Rice [7] used a scalar quantity called J-integral which predicts that the rate of energy release increases proportionally with the propagation of the semi-infinite crack at presence of the disturbance zone. Consequently, the J-integral can be used to determine the rate of energy release related to the translational deformation of the damage zone at crack tip [41]. This energy is applied to materials with brittle behavior and it is considered to be an essential parameter of failure [6]. In linear elasticity, the strain energy is given by the following formula according to constraints and strains of material [42]:

$W=\frac{1}{2}\left(\sigma_{11} \varepsilon_{11}+\sigma_{22} \varepsilon_{22}+2 \sigma_{12} \varepsilon_{12}\right)(13)$

In a brittle material, the external loads produce very high constraints but the strains are very small, that is to say ; $\varepsilon_{11} \simeq \varepsilon_{12} \simeq \varepsilon_{22} \simeq \varepsilon \simeq 0$. For this reason, the strain energy (Equation (13)) can be written in the following form:

$W=\frac{\varepsilon}{2}\left(\sigma_{11}+\sigma_{22}+2 \sigma_{12}\right)(14)$ 
Based on the plane constraints, one can determine the strain energy generated by the interaction between the semi-infinite crack and the neighboring microcrack. The substitution of Equations (10) to (12) into Equation (14), brings us the energy of deformation under the following expression:

$W=\frac{2 . \mu b \varepsilon}{\pi(1+k) \rho}[\cos (\alpha+\theta)+\sin (\theta) \sin (\alpha-2 \theta)](15)$

\section{III.2.1 Orientation of the micro-crack around the semi-infinite crack}

The orientation of the microcrack around itself and around semi-infinite crack, gives the strain energy in each point of the material. By fixing the orientation of microcrack around itself and varying the orientation angle of microcrack around the semi-infinite crack, the following figures (figure 4(a,b) to $8(a, b)$ ) present the strain energy values found around the semi-infinite crack.

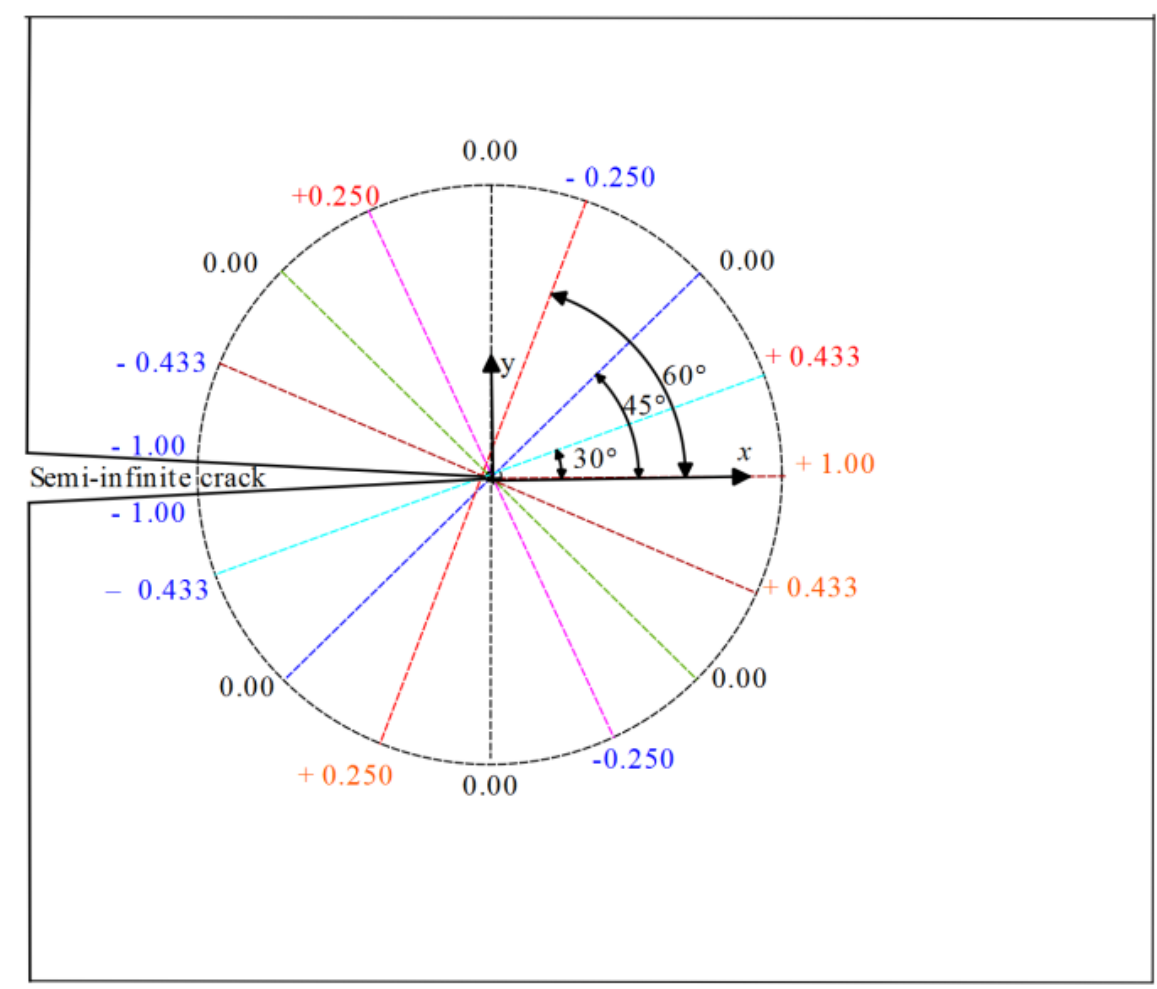




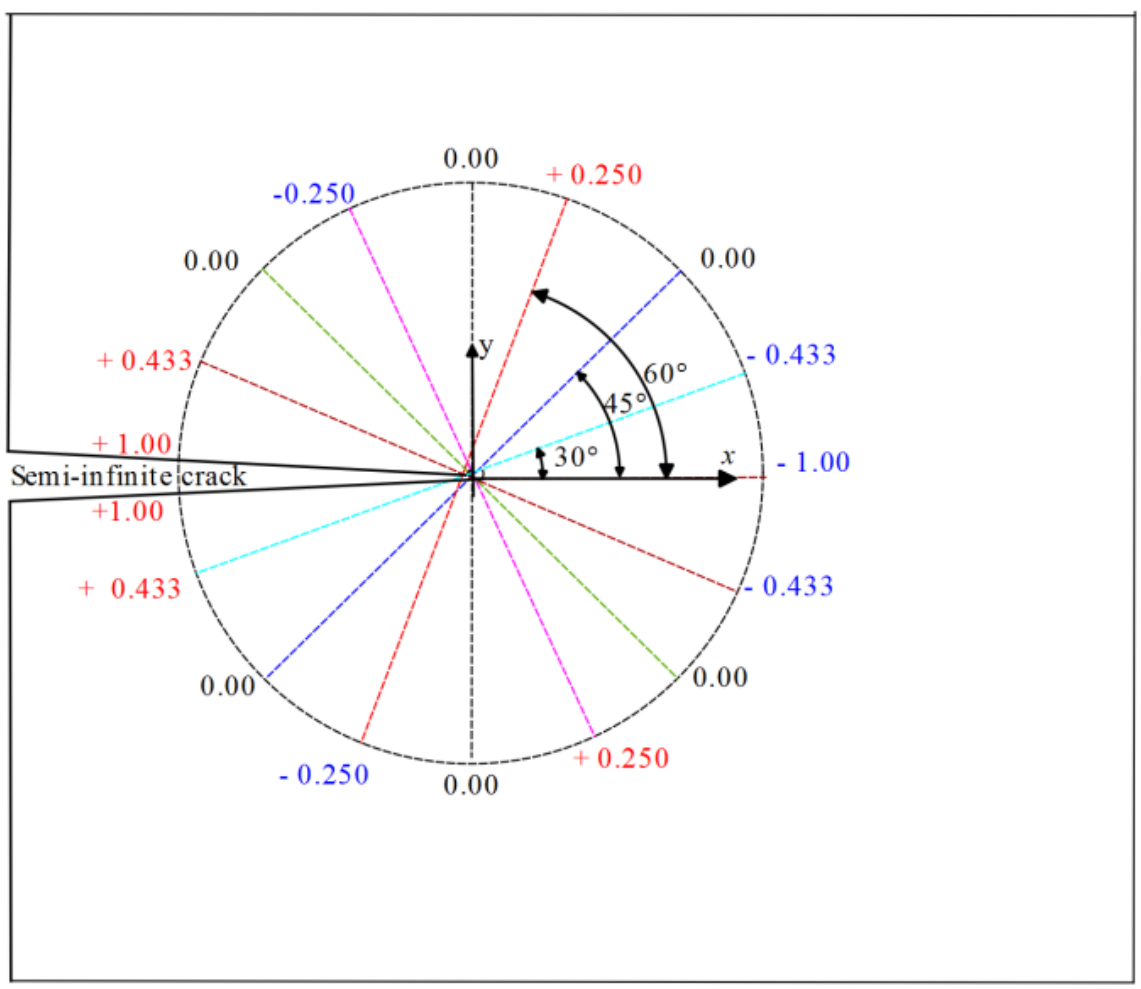

a) b)

Fig.4 Strain energy values around the semi-infinite crack (case of micro-crack is parallel to the semi-infinite (rack);a) $=0, \mathrm{~b})=\pi$ 

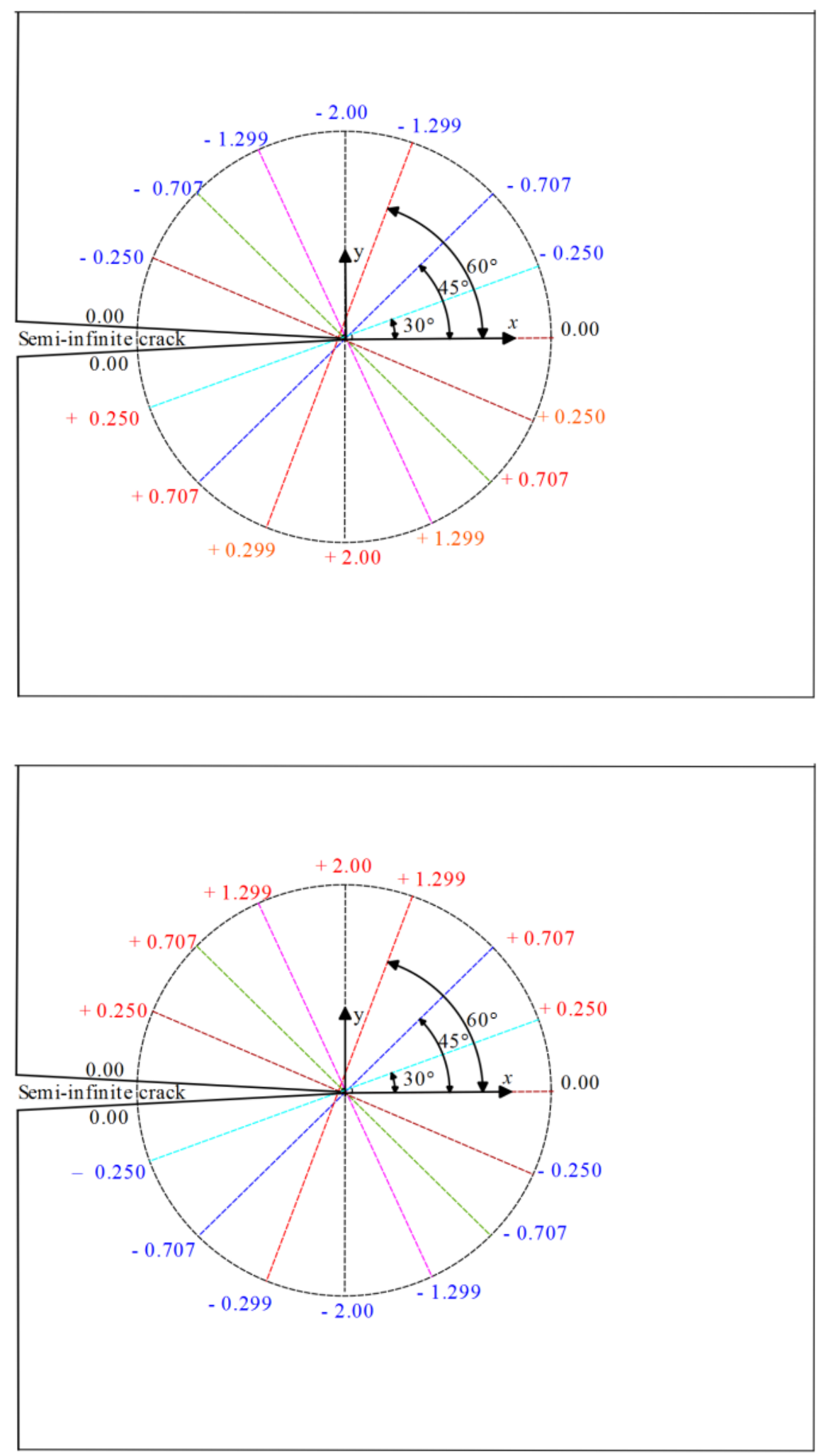

a) b) 
Fig. 5 Strain energy values around the semi-infinite crack (case of micro-crack is perpendicular to the semi-infinite (rack) ; a) $=\pi / 2, \mathrm{~b})=3 \pi / 2$

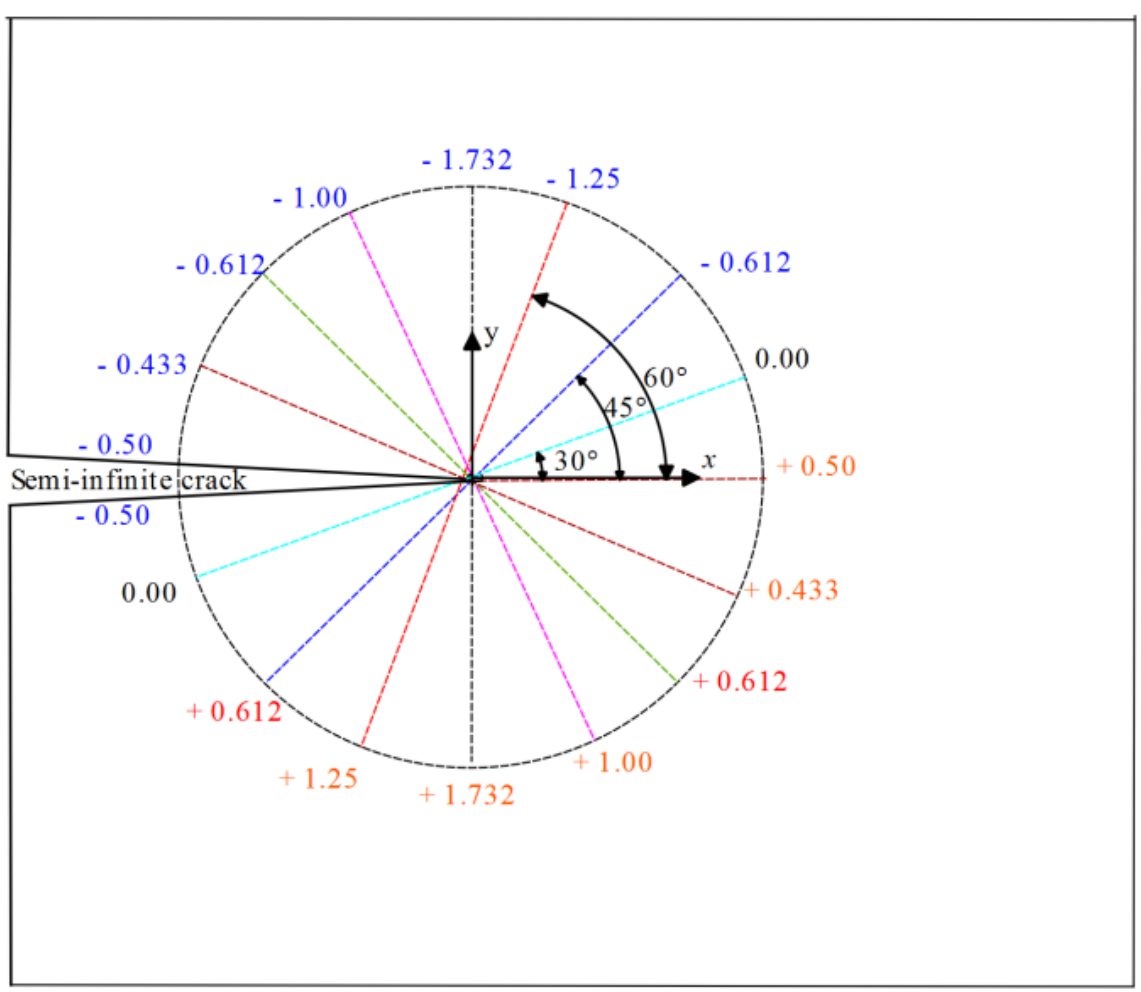




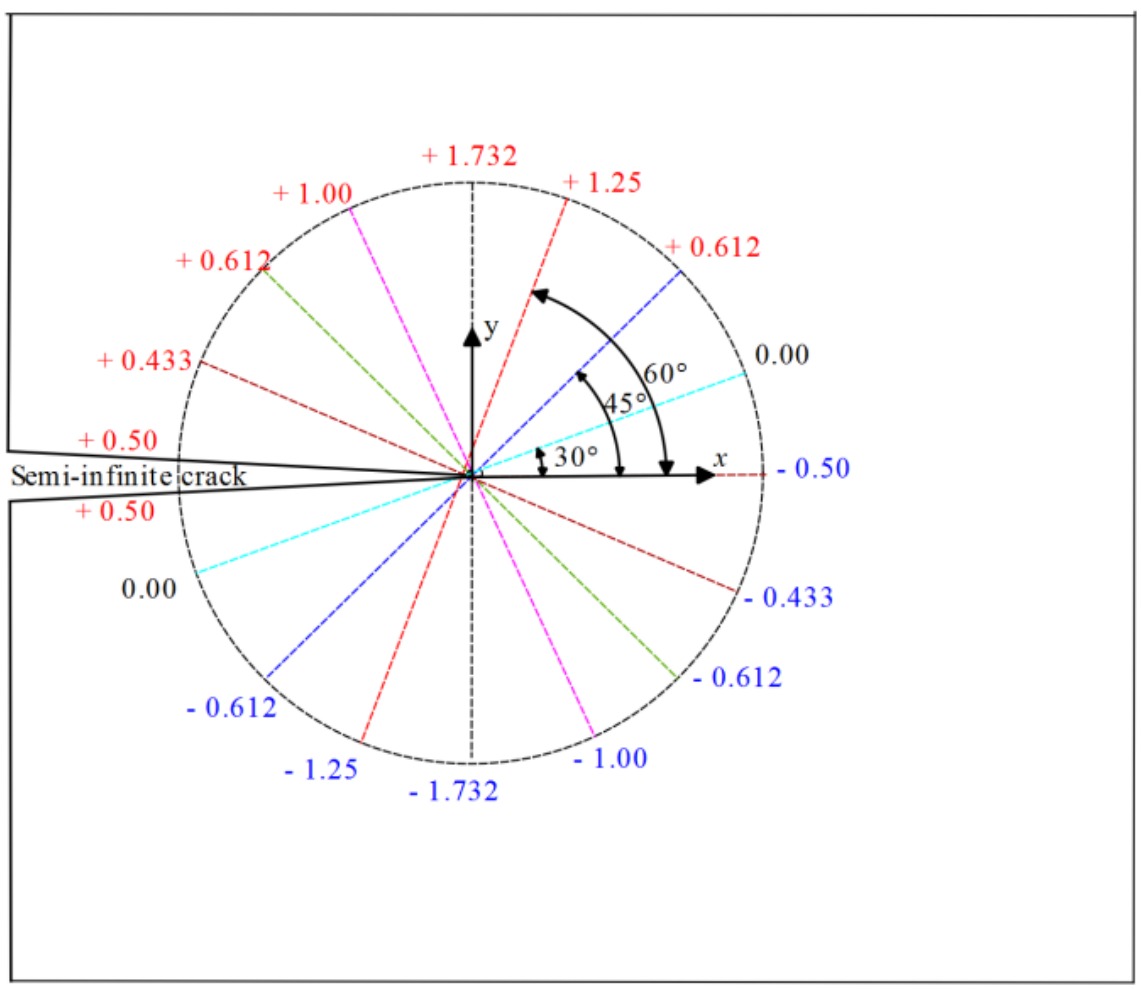

a) b)

Fig.6 Strain energy values around the semi-infinite crack; a) $=\pi / 3, b)=-\pi / 3$ 

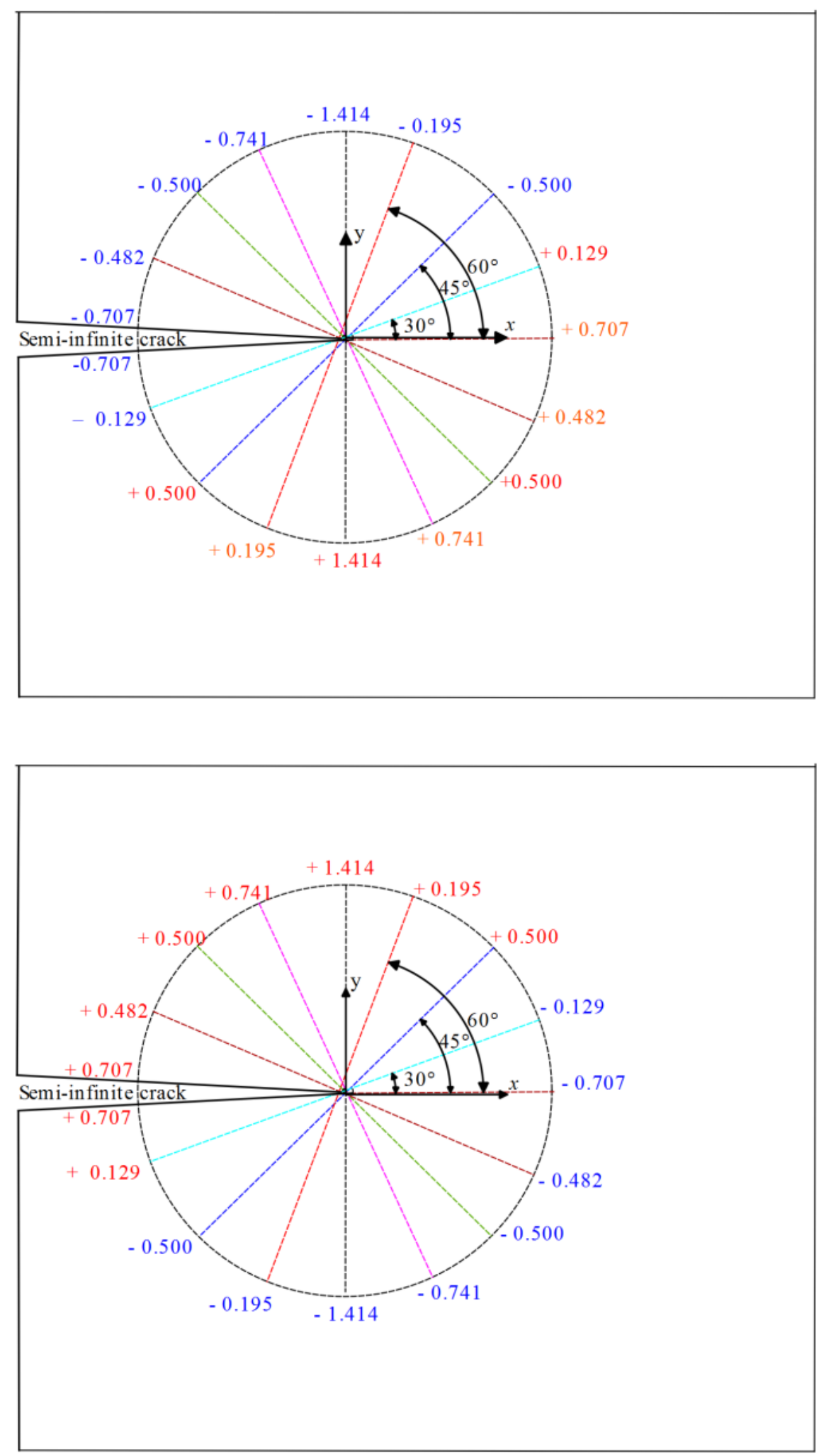

a) b) 
Fig.7 Strain energy values around the semi-infinite crack; a) $=\pi / 4, b)=-\pi / 4$
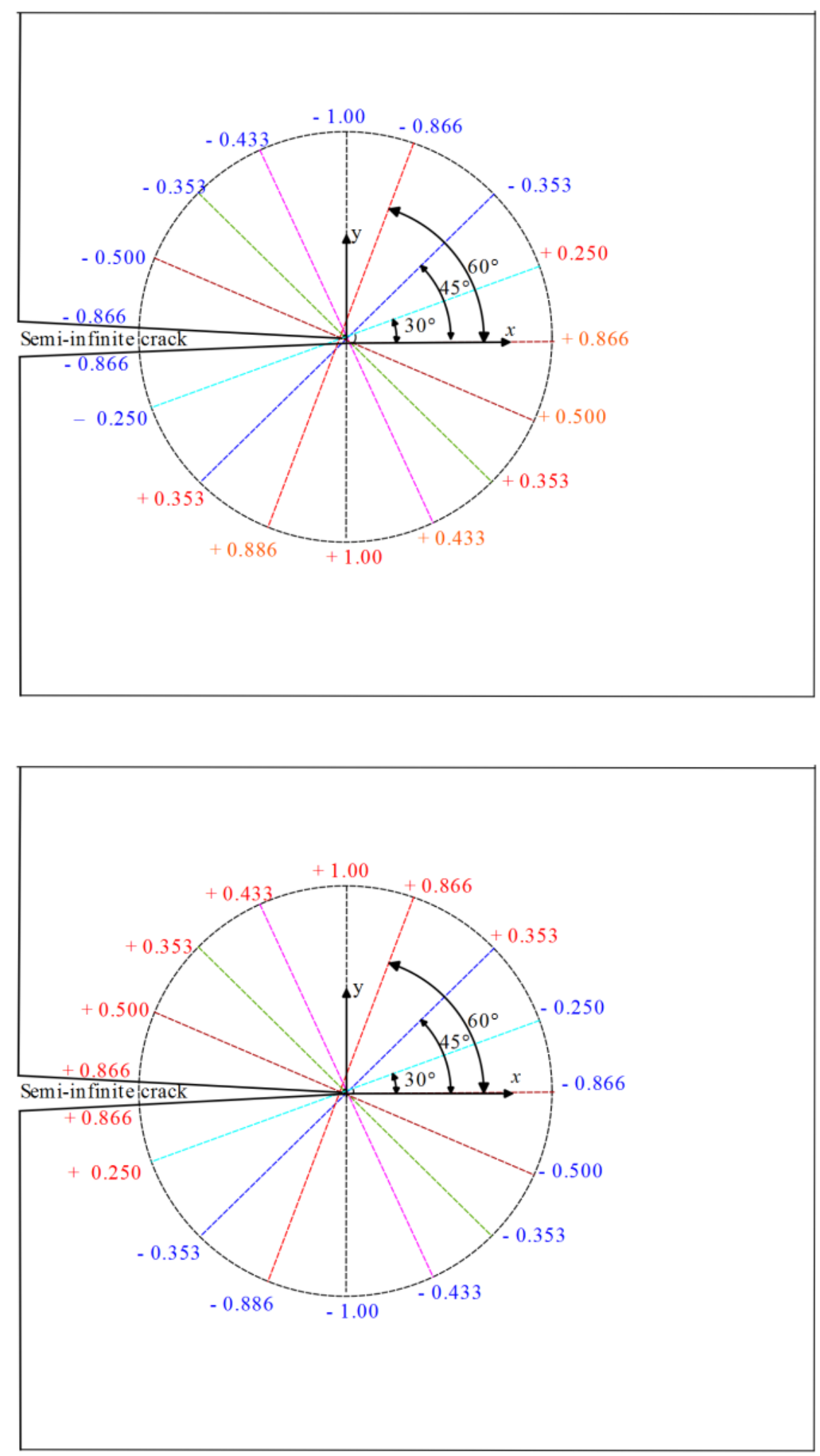
a) b)

Fig.8 Strain energy values around the semi-infinite crack; a) $=\pi / 6, b)=-\pi / 6$

by fixing the angle of orientation of the micro-crack around herself, the Figures 9 to 12 show the variation of strain energy according to the angle of orientation of micro-crack around the semi-infinite crack.

\section{Hosted file}

image16.wmf available at https://authorea.com/users/348620/articles/473833-influence-ofmicro-crack-on-the-propagation-of-a-semi-infinite-crack

Fig. 9 Strain energy vs. orientation angle of the micro-crack around the semi-infinite crack ; case of microcrack is parallel to the semi-infinite crack

\section{Hosted file}

image17.wmf available at https://authorea.com/users/348620/articles/473833-influence-ofmicro-crack-on-the-propagation-of-a-semi-infinite-crack

Fig. 10 Strain energy variation as function of the orientation angle of the micro-crack around the semi-infinite crack ; in case of micro-crack is perpendicular to the semi-infinite crack

\section{Hosted file}

image18.wmf available at https://authorea.com/users/348620/articles/473833-influence-ofmicro-crack-on-the-propagation-of-a-semi-infinite-crack

Fig. 11 Strain energy variation as function of the orientation angle of the micro-crack around the semi-infinite crack ; in case of micro-crack is inclined by $\pi / 4$ compared to semi-infinite crack.

\section{Hosted file}

image19.wmf available at https://authorea.com/users/348620/articles/473833-influence-ofmicro-crack-on-the-propagation-of-a-semi-infinite-crack

Fig. 12 Strain energy vs. orientation angle of the micro-crack around the semi-infinite crack ; case of micro-crack is inclined by $\pi / 6$ compared to semi-infinite crack.

\section{III.2.2 Orientation of micro-crack around itself}

The orientation of microcrack around itself generates constraints, displacements, strain energy and consequently influence on the propagation of the crack [3]. In this case, one maintains the orientation angle of microcrack around semi-infinite crack and varies the orientation of this microcrack around itself, the Figures13 to16 show the variation of the strain energy as a function of the orientation angle of the microcrack around itself.

\section{Hosted file}

image20.wmf available at https://authorea.com/users/348620/articles/473833-influence-ofmicro-crack-on-the-propagation-of-a-semi-infinite-crack

Fig. 13 Strain energy vs. orientation angle of the micro-crack around itself

; case of micro-crack is parallel and perpendicular compared to $x-x$ axis.

\section{Hosted file}

image21.wmf available at https://authorea.com/users/348620/articles/473833-influence-ofmicro-crack-on-the-propagation-of-a-semi-infinite-crack

Fig. 14 Strain energy vs. orientation angle of the micro-crack around itself 
; case of micro-crack is inclined by $\pi / 3$ compared to $x-x$ axis.

\section{Hosted file}

image22.wmf available at https://authorea.com/users/348620/articles/473833-influence-ofmicro-crack-on-the-propagation-of-a-semi-infinite-crack

Fig. 15 Strain energy vs. orientation angle of the micro-crack around itself

; case of micro-crack is inclined by $\pi / 4$ compared to $x-x$ axis.

\section{Hosted file}

image23.wmf available at https://authorea.com/users/348620/articles/473833-influence-ofmicro-crack-on-the-propagation-of-a-semi-infinite-crack

Fig. 16 Strain energy vs. orientation angle of the micro-crack around itself

; in case of micro-crack is inclined by $\pi / 6$ compared to $x-x$ axis.

\section{Results and discussions}

In this research, the results of strain energy found during the positioning of micro-crack with respect to the semi-infinite crack, limit areas of amplification, reduction and sometimes arrest of the propagation of semi-infinite crack.

- According to Figures 4 (a, b) - 8 (a, b), whatever the positioning of micro-crack compared to the semi-infinite crack $(\forall \alpha \epsilon[0,2 \pi]$ and $\forall \theta \epsilon[0,2 \pi])$, the values of strain energy are symmetrical with respect to the point of semi - infinite crack.

- From Figure 4 (a, b), in case of the micro-crack is parallel with respect to the semi-infinite crack $(=$ 0 et $=\pi)$, the strain energy is zero if this micro-crack is located on the axis $\mathrm{y}-\mathrm{y}\left(=90^{\circ}\right.$ and $\left.=270^{\circ}\right)$, and reaches the maximum value when this micro-crack is located in axis $x-x\left(=0^{\circ}\right.$ et $\left.=180^{\circ}\right)$.

- On other, the Figure $5(\mathrm{a}, \mathrm{b})$ represents a micro-crack perpendicular to the semi-infinite crack $(=\pi / 2$ et $=3 \pi / 2$ ). The strain energy is zero if the micro-crack is located on the $x-x$ axis and reaches the maximum value when this micro-crack is located on the $y$-yaxis.

- Figures 9-12 represent variation of the strain energy and consequently the amplification or reduction of the propagation of semi-infinite crack according to the orientation of micro-crack around itself and around semi-infinite crack. The Table 1 summarizes the areas of amplification, reduction and also arrest of propagation of the semi-infinite crack.

Table 1 area of amplification, reduction and arrest of the propagation of the semi-infinite crack

\begin{tabular}{llllll}
\hline Figures & $\left(^{\circ}\right)$ & $\alpha(\mathrm{rad})$ & Effect & $\alpha(\mathrm{rad})$ & Effect \\
\hline Figure 9 & {$[0-45]$} & 0 & Amplified & $\pi$ & Reduce \\
& {$[45-90]$} & & Reduce & & Amplified \\
& {$[90-135]$} & & Amplified & & Reduce \\
& {$[135-225]$} & & Reduce & & Amplified \\
& {$[225-270]$} & & Amplified & & Reduce \\
& {$[270-315]$} & & Reduce & & Amplified \\
& {$[315-360]$} & & Amplified & & Reduce \\
Figure 10 & {$[0-11]$} & $\pi / 2$ & Arrest & $3 \pi / 2$ & Arrest \\
& {$[11-166]$} & & Reduce & & Amplified \\
& {$[166-192]$} & & Arrest & & Arrest \\
& {$[192-349]$} & & Amplified & & Reduce \\
& {$[349-360]$} & & Arrest & & Arrest \\
Figure 11 & {$[0-34]$} & $\pi / 4$ & Amplified & $5 \pi / 4$ & Reduce \\
& {$[534-215]$} & & Reduce & & Amplified
\end{tabular}




\begin{tabular}{llllll}
\hline Figures & $\left({ }^{\circ}\right)$ & $\alpha(\mathrm{rad})$ & Effect & $\alpha(\mathrm{rad})$ & Effect \\
\hline & {$[215-360]$} & & Amplified & & Reduce \\
& {$[0-149]$} & $3 \pi / 4$ & Reduce & $7 \pi / 4$ & Amplified \\
& {$[149-327]$} & & Amplified & & Reduce \\
& {$[327-360]$} & & Reduce & & Amplified \\
Figure 12 & {$[0-37]$} & $\pi / 6$ & Amplified & $7 \pi / 6$ & Reduce \\
& {$[37-215]$} & & Reduce & & Amplified \\
& {$[215-360]$} & & Amplified & & Reduce \\
& {$[0-29]$} & $\pi / 3$ & Amplified & $4 \pi / 3$ & Reduce \\
& {$[29-212]$} & & Reduce & & Amplified \\
& {$[212-360]$} & & Amplified & & Reduce \\
& {$[0-150]$} & $2 \pi / 3$ & Reduce & $5 \pi / 3$ & Amplified \\
& {$[150-329]$} & & Amplified & & Reduce \\
& {$[329-360]$} & & Reduce & & Amplified \\
& {$[0-143]$} & $5 \pi / 6$ & Reduce & $11 \pi / 6$ & Amplified \\
& {$[143-324]$} & & Amplified & & Reduce \\
& {$[324-360]$} & & Reduce & & Amplified \\
\hline
\end{tabular}

By maintaining the positioning of micro-crack with respect to semi-infinite crack and varying the orientation of this micro-crack around itself, Figures 13-16 represents the effect of the micro-crack on the strain energy and the propagation of semi-infinite crack. Table 2, groups the zones of amplification and reduction of semi-infinite crack

Table 2 Amplification and reduction zones of propagation of semi-infinite crack according to the orientation of micro-crack around itself

\begin{tabular}{|c|c|c|c|c|c|}
\hline Figures & $\alpha\left({ }^{\circ}\right)$ & $(\mathrm{rad})$ & Effect & $(\mathrm{rad})$ & Effect \\
\hline \multirow[t]{5}{*}{ Figure 13} & $0-90$ & 0 & Amplified & $\pi$ & Reduce \\
\hline & $90-270$ & & Reduce & & Amplified \\
\hline & $270-360$ & & Amplified & & Reduce \\
\hline & $0-180$ & $\pi / 2$ & Amplified & $3 \pi / 2$ & Reduce \\
\hline & $180-360$ & & Reduce & & Amplified \\
\hline \multirow[t]{6}{*}{ Figure 14} & $0-166$ & $\pi / 3$ & Reduce & $4 \pi / 3$ & Amplified \\
\hline & $166-349$ & & Amplified & & Reduce \\
\hline & $349-360$ & & Reduce & & Amplified \\
\hline & $0-11$ & $2 \pi / 3$ & Amplified & $5 \pi / 3$ & Reduce \\
\hline & 11- 192 & & Reduce & & Amplified \\
\hline & $192-360$ & & Amplified & & Reduce \\
\hline \multirow[t]{2}{*}{ Figure 15} & $0-180$ & $\pi / 4$ and $5 \pi / 4$ & Reduce & $3 \pi / 4$ and $7 \pi / 4$ & Amplified \\
\hline & $180-360$ & & Amplified & & Reduce \\
\hline \multirow[t]{6}{*}{ Figure 16} & $0-60$ & $\pi / 6$ & Reduce & $7 \pi / 6$ & Amplified \\
\hline & $60-240$ & & Amplified & & Reduce \\
\hline & $240-360$ & & Reduce & & Amplified \\
\hline & $0-122$ & $5 \pi / 6$ & Reduce & $11 \pi / 6$ & Amplified \\
\hline & $122-300$ & & Amplified & & Reduce \\
\hline & $300-360$ & & Reduce & & Amplified \\
\hline
\end{tabular}

According to Table 1, the presence of microcrack in vicinity of the semi-infinite crack, can amplify, reduce and also arrest the propagation of semi-infinite crack. whatever the positioning of microcrack with respect to the 
semi-infinite crack $(\forall \alpha \epsilon[0,2 \pi]$ and $\forall \theta \epsilon[0,2 \pi])$, the tables 3-4 summarize the amplification, reduction zones and arresting the propagation of the semi-infinite crack.

Table 3 Amplification and reduction zones of the propagation of semi-infinite crack.

In case ; $\alpha \epsilon[0, \pi / 2[\cup] \pi / 2, \pi] \cup[\pi, 3 \pi / 2[\cup] 3 \pi / 2,2 \pi]$ and $\forall \theta \epsilon[0,2 \pi]$

\begin{tabular}{lll}
\hline$\alpha(\mathrm{rad})$ & $\left({ }^{\circ}\right)$ & Effect \\
\hline$[0, \pi / 2[$ & $0-30$ & Amplified \\
& $45-90$ & Reduce \\
& $315-360$ & Amplified \\
]$\pi / 2, \pi]$ & $0-45$ & Reduce \\
& $150-215$ & Amplified \\
& $330-360$ & Reduce \\
{$[\pi, 3 \pi / 2[$} & $0-30$ & Reduce \\
& $45-90$ & Amplified \\
& $315-360$ & Reduce \\
] $3 \pi / 2,2 \pi]$ & $0-45$ & Amplified \\
& $150-215$ & Reduce \\
& $330-360$ & Amplified \\
\hline
\end{tabular}

Table 4 Amplification, reduction and arrest zones of the propagation of semi-infinite crack.

In case of $; \alpha=\pi / 2, \alpha=3 \pi / 2$ and $\forall \theta \epsilon[0,2 \pi]$

\begin{tabular}{lll}
\hline$\left(^{\circ}\right)$ & Efect & Efect \\
\hline$[0-11]$ & $\alpha=\pi / 2$ & $\alpha=3 \pi / 2$ \\
{$[11-166]$} & Arrest & Arrest \\
{$[166-192]$} & Reduce & Amplified \\
{$[192-349]$} & Arrest & Arrest \\
{$[349-360]$} & Amplified & Reduce \\
\hline
\end{tabular}

\section{Conclusion}

In this research work, the main objective is to determine the effect of micro-crack on the semi-infinite crack by determining the strain energy and limiting the zones of amplification, reduction and sometimes arrest of propagation of semi-infinite crack. According to the Figures 4-16, whatever the positioning of the micro-crack compared to semi-infinite crack, the strain energy values are symmetrical with respect to the semi-infinite crack tip. The results of strain energy summarized in Tables 1- 4, show that the zones of amplification, reduction and arrest of propagation of semi-infinite crack are symmetrical compared to the point of semi-infinite crack tip. By varying the orientation angles ( and $\alpha$ ), the Table 3 summarizes all zones of amplification and reduction and presents a symmetry in the effect on the propagation of semi-infinite

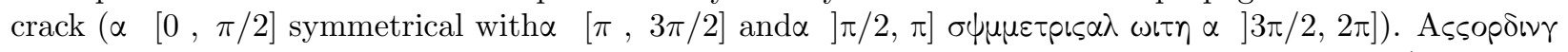

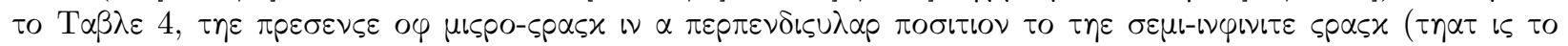
$\sigma \alpha \psi \cdot \alpha=\pi / 2$ and $\alpha=3 \pi / 2)$, can also arrest the propagation of crack in the zones ; $\vartheta[0,11],\left[166^{\circ}-192^{\circ}\right]$ and $\left[349^{\circ}-360^{\circ}\right]$.

\section{References}

1. A. A. Rubinstein. Macrocrack-Microdefect Interaction. J. Appl. Mech. 1986 ; 53 :505-510. 
2. Sham-Tsong Shiue and Sanboh Lee. The elastic interaction between screw dislocations and cracks emanating from an elliptic hole. J. of Appl. Phys . $1988 ; 64: 129$.

3. Xiaotao Li, Hongda Yang, Xiaodong Zan, Xu Li and Xiaoyu Jiang. Effect of a micro-crack on the kinked macro-crack. Theor. Appl. Fract. Mech. 2018 ; 96 : 468-475.

4 Hamid Hamli Benzahar. Theoretical and numerical analysis of stress and stress intensity factor in bi material. Int. J. Struct. Integr. $2019 ; 10: 76-84$.

5. T. Y. Zhang and J. C. M. Li. Interaction of an edge dislocation with an interfacial Crack. Int. J. Appl. Phys. $1992 ; 72 ; 2215$.

6. Ankang Cheng, Nian-Zhong Chen and Yongchang Pu. An energy principles based model for fatigue crack growth prediction.Int.. J. of Fat, 2019;128 : 105198.

7. J. R. Rice. A Path Independent Integral and the Approximate Analysis of Strain Concentration by Notches and Cracks.J. Appl. Mech . 1968; 35: 379-386.

8. Dorothee Knees. Griffith-formula and j-integral for a crack in a power-law hardening material. Math. Models Meth. Appl. Sciences. 2006; $16: 1723-1749$.

9. D.V. Bambill, C.A. Rossit and A. Susca. Numerical experiments on the determination of stress concentration factors in orthotropic perforated plates subjected to in - plane loading. Struct. Eng. Mech . 2009 ; $32 ; 549-561$.

10. H. Hamli Benzahar and Mohamed Chabaat. Damage Zone Size Limit During the Crack Propagation. Period. Polyt. Civil Eng. 2020; 64 : 73-80.

11. A. A.Griffith. The phenomana of rupture and flow in solid, Philosophical translation. Royal Soc of London, Serie A . 1921; 221: 163-198.

12. Škec, L., Alfano, G. \& Jelenić, G. Complete analytical solutions for double cantilever beam specimens with bi-linear quasi-brittle and brittle interfaces. Int. J. Fract. $2019 ; 215$ : 1-37.

13. Tian-hu Hao. Cod of a crack in viscoelastic perfectly plastic material. Int. J. Fract.. $1992 ; 56$.

14. Rong Luo and Hui Chen. An improved method of characterizing fracture resistance of asphalt mixtures using modified Paris' law: Part II-Establishment of index for fracture resistance. Mech. Mater. 2019 ; $138 ; 103168$.

15. Mohammad Hossein Ahmadi and Hamed Molladavoodi. A micromechanical Sliding-Damage Model Under Dynamic Compressive Loading. Period Polyt. Civil Eng . 2019 ; 63 : 168-183.

16. W.-S. Lei. Statistics of single-fibre tensile strength incorporating spatial distribution of microcracks. Fract Eng Mater Struct . 2016 ; 39 :1337-1351.

17. Reaz A. Chaudhuri. On through-thickness distribution of stress intensity factors and energy release rates in the vicinity of crack fronts.Engineering Fracture Mechanics. $2019 ; 216$ : 106478.

18. Williams, M. L. On the Stress Distribution at the Base of a Stationary Crack. J. Appl. Mech . 1956 ; $24: 109-114$.

19. Atkinson, C. and Eshelby J. D. The flow of energy into the tip of a moving crack. Int. J. Fract . 1984 ; $26: 316-321$.

20. X. G. Wang, H. R. Ran, C. Jiang and Q. H. Fang. An energy dissipation-based fatigue crack growth model,Int. J. Fat. $2018 ; 114: 167-176$.

21. G. Irwin. Analyses of stresses and strains near end of crack traversing a plate. J. Appl. Mech . 1957 ; $24: 351-369$. 
22. Hadei, M. R., Kemeny, J., Ghazvinian, A., Rezaiepoor, A., Sarfarazi, V. New Development to Measure Mode I. Fracture Toughness in Rock.Period. Polyt. Civil Eng . 2017 ; 61 : 51-55.

23. Seyed Mohammad Javad Razavi and Filippo Berto. A new fixture for fracture tests under mixed mode I/II/III loading. Fat. Fract. Eng. Mater. Struct . $2019 ; 42$ : 1874-1888.

24. Iarley Loan SampaioLibos and Liang Cui. Effects of curing time, cement content, and saturation state on mode-I fracture toughness of cemented paste backfill.Eng. Fract. Mech. $2020 ; 235$ : 107174.

25 Victor I. Rizov. Non-linear study of mode II delamination fracture in functionally graded beams. Steel Comp. Struct. $2017 ; 23: 263-271$.

26. Mojtaba Mahmoudi Monfared. Mode III SIFs for interface cracks in an FGM coating-substrate system. Struct. Eng. Mech . 2017 ; 64 : 71-79.

27. Alexey Nikolaevich Savkin, Alexander Alexandrovich Sedov and Artem Valerievich Andronik. The steel damageability simulation under random loading by the power, energetical and strain fracture criterions, Period. Polyt. Mech. Eng. 2014; 58: 119-126.

28. Liu Zhenyu, Wang Chuang, Duan Guifang and Tan Jianrong. A new refined plate theory with isogeometric approach for the static and buckling analysis of functionally graded plates.Int. J. Mech. Sciences. $2019 ; 162: 105036$.

29. S.S Bhadauria, M.S Hora, K.K Pathak. Effect of Stress Triaxiality on Yielding of Anisotropic Materials under Plane Stress Condition. J. Solid Mech . $2019 ; 1$ : 226-232.

30. H. Hamli Benzahar and M. Chabaat. Crack in brittle material at presence of a dislocation, Advanc. Mater. Resear . 2014; 921:2043- 2047.

31. H Hadjab-Souag, J. F. Thimus and Mchabaat. Detecting the fracture process zone in concrete using scanning electron microscopy and numerical modelling using the nonlocal isotropic damage model. Canad. J. Civil Eng . 2007; 34: 496-504.

32. P Gallo, T Sumigawa, T Kitamura, F Berto. Evaluation of the strain energy density control volume for a nanoscale singular stress field. Fat. Fract Eng. Mater Struct.2016 ; 39 : 1557-1564.

33. Tong-Yi Zhang, J. E. Hack and L. J. Guido. An array of dislocations in a strained epitaxial layer. 1. Elastic energy.J. appl. phys. 1994; 75 : 2358-2362.

34. H. Hamli benzahar and M. Chabaat. Stress field and energy analysis during the fracture of composite materials. Appl. Mech. Mater.2014; 532 : 524-533.

35. Flavio V.Souza and David H.Allen. Modeling the transition of microcracks into macrocracks in heterogeneous viscoelastic media using a two-way coupled multiscale model. Int. J. Solids Struct. 2011; 48: $3160-3175$.

36. A. Corfdir and G. Bonnet. Exact degenerate scales in plane elasticity using complex variable methods.Int. J. Solids Struct. $2016 ; 80$ : 430-444.

37. Ming-Yuan He and John W. Hutchinson. Kinking of a crack out of an interface, Int. J. Appl. Mech. $1989 ; 56: 270-278$.

38. W.-Y. TIAN and Y.-H. CHEN. Arbitrarily oriented microcracks near the tip of an interface macrocrack in bonded dissimilar anisotropic materials. Fat. Fract. Eng. Mater. Struct . 2004 ; 27: 379-390.

39. S. SHAHROOI , I. H. METSELAAR and Z. HUDA. Evaluating a strain energy fatigue method using cyclic plasticity models. Fat. Fract. Eng. Mater. Struct. 2010 ; 33 : 530-537.

40. H. Ayas, H. Hamli Benzahar, M. Chabaat, Energy Release Rate during the Cracking of Composite Materials. Energy Proced . $2015 ; 74$ : 1040-1047. 
41. Szekrényes A. J-integral for delaminated beam and plate models. Period. Polytech. Mech. Eng . 2012 ; $56: 63-71$.

42. C. O. Horgan. On the strain-energy density in linear elasticity. J. Eng. Math . $1973 ; 7$ : 231-234.

Hosted file

tables.rar available at https://authorea.com/users/348620/articles/473833-influence-ofmicro-crack-on-the-propagation-of-a-semi-infinite-crack

\section{Hosted file}

figures.rar available at https://authorea.com/users/348620/articles/473833-influence-ofmicro-crack-on-the-propagation-of-a-semi-infinite-crack 